\title{
Met receptor-induced Grb2 or Shc signals both promote transformation of intestinal epithelial cells, albeit they are required for distinct oncogenic functions
}

Véronique Pomerleau, Mélissa Landry, Jimmy Bernier, Pierre H Vachon and Caroline Saucier ${ }^{*}$

\begin{abstract}
Background: Deregulation of receptor tyrosine kinases (RTK) contributes to the initiation and progression of intestinal-derived epithelial cancers, including colorectal cancer (CRC). However, the roles of the proximal signaling molecules engaged by RTKs in different oncogenic functions of CRC remain unclear.

Methods: Herein, the functional impact of expressing variant forms of the oncogenic Met receptor (Tpr-Met) that selectively recruit the adaptor proteins Grb2 or Shc was investigated in a model derived from normal intestinal epithelial cells (IEC-6). An RNA interference (RNAi) approach was used to define the requirement of Grb2 or Shc in Tpr-Met-transformed IEC-6 cells. Since Grb2 and Shc couple RTKs to the activation of the Ras/MEK/Erk and PI3K/ Akt pathways, Erk and Akt phosphorylation/activation states were monitored in transformed IEC-6 cells, and a pharmacological approach was employed to provide insights into the roles of these pathways in oncogenic processes evoked by activated Met, and downstream of Grb2 and Shc.

Results: We show, for the first time, that constitutive activation of either Grb2 or Shc signals in IEC-6 cells, promotes morphological transformation associated with down-regulation of E-cadherin, as well as increased cell growth, loss of growth contact inhibition, anchorage-independent growth, and resistance to serum deprivation and anoikis. Oncogenic activation of Met was revealed to induce morphological transformation, E-cadherin down-regulation, and protection against anoikis by mechanisms dependent on Grb2, while Shc was shown to be partly required for enhanced cell growth. The coupling of activated Met to the Ras/MEK/Erk and PI3K/Akt pathways, and the sustained engagement of Grb2 or Shc in IECs, was shown to trigger negative feedback, limiting the extent of activation of these pathways. Nonetheless, morphological alterations and E-cadherin down-regulation induced by the oncogenic Tpr-Met, and by Grb2 or Shc signals, were blocked by MEK, but not PI3K, inhibitors while the enhanced growth and resistance to anoikis induced by Tpr-Met were nearly abolished by co-treatment with both inhibitors.
\end{abstract}

Conclusion: Overall, these results identify Grb2 and Shc as central signaling effectors of Met-driven progression of intestinal epithelial-derived cancers. Notably, they suggest that Grb2 may represent a promising target for the design of novel CRC therapies.

Keywords: Receptor tyrosine kinase, Grb2, Shc, Met, Intestinal epithelial cell, Transformation, Proliferation, Anoikis, MAPK, PI3K, Colorectal cancer

\footnotetext{
* Correspondence: caroline.saucier@usherbrooke.ca

Department of Anatomy and Cell Biology, Faculty of Medicine and Health

Sciences, Université de Sherbrooke, 3201, rue Jean-Mignault, Sherbrooke,

Quebec J1E 4K8, Canada
}

\section{Biomed Central}

(c) 2014 Pomerleau et al.; licensee BioMed Central Ltd. This is an Open Access article distributed under the terms of the Creative Commons Attribution License (http://creativecommons.org/licenses/by/2.0), which permits unrestricted use, distribution, and reproduction in any medium, provided the original work is properly credited. The Creative Commons Public Domain Dedication waiver (http://creativecommons.org/publicdomain/zero/1.0/) applies to the data made available in this article, unless otherwise stated. 


\section{Background}

When activated, cell surface growth factor receptor tyrosine kinases (RTK) become phosphorylated at a number of tyrosine (Tyr) residues. Many of those located within the cytoplasmic tail of the receptor create binding sites for proteins containing Src homology 2 (SH2) and phosphotyrosinebinding (PTB) domains, which recognize phospho-Tyr residues within the context of specific adjacent amino acids. Proteins recruited to RTKs include enzymes, such as phospholipase $\mathrm{C} \gamma$ (PLCY) and phosphatidylinositol 3-kinase (PI3K); and adaptor proteins, including growth factor receptor-bound protein-2 (Grb2) and Src-homology collagen (Shc) proteins. These latter proteins contain multiple protein-protein interactions motifs. The resulting complex relays and amplifies an exquisitely fine-tuned regulation of multiple downstream signaling events, which depending on cellular context, mediate specific biological responses (reviewed in [1]). This regulation is perturbed in cancers, including those of intestinal epithelial cell (IEC) origin such as colorectal cancer (CRC).

Deregulation of RTKs in CRC commonly involves the over-expression of the receptor and/or its ligand. As illustrated by the Met/hepatocyte growth factor (HGF) and epidermal growth factor receptor (EGFR) signaling axis, this dysregulation often takes place at the earliest stages of the disease and it is observed in virtually all metastatic CRC (reviewed in [2-4]). Ligand or receptor deregulation may result in a lower threshold for growth factor stimulation, autocrine/paracrine ligand-receptor activation loops, and even ligand-independent constitutive receptor activation. Regardless of the mechanisms of RTK oncogenic activation, the outcome is the loss of the normally fine-tuned regulation of downstream signaling, which may ultimately contribute to the acquisition of cancer properties. Notably, its has been shown that the expression of constitutively activated forms of the Met receptor in non-transformed IECs promoted morphological transformation; enhanced proliferation rate; induced loss of both growth contact inhibition and anchorage-dependent growth; and increased in vivo angiogenic, tumorigenic, and metastatic capacities $[5,6]$.

Studies performed predominantly in fibroblast and breast cancer cell models have revealed that Grb2 and Shc adaptor proteins are among the signaling proteins that, upon recruitment by activated RTKs, mediate events directly linked to the initiation and progression of cancer [7-12]. Many RTKs interact directly with Grb2, some rely on Shc family adaptors to recruit Grb2, and others do both [1]. While direct Grb2/RTK interactions involve binding of the Grb2 SH2 domain to pYXNX motifs, Shc proteins interact with RTKs primarily through the binding of their N-terminal PTB domain to NPXPY motifs. The latter results in phosphorylation of Tyr residues within the Shc central collagen-homology domain
$1(\mathrm{CH} 1)$. These phosphorylated tyrosine residues constitute consensus-binding sites for the Grb2 SH2 domain, thus allowing Shc to engage Grb2-driven signaling pathways (reviewed in [13]). The best-characterized role of the two adaptor proteins, Grb2 and Shc, is to link RTKs to the activation of the Ras/Raf/MEK/Erk mitogenic (Ras/MAPK) pathway. The constitutive association of the N-terminal Grb2 SH3 domain with the Ras guanine nucleotide exchange factor, Son of Sevenless (SOS) constitutes one component of this connection [1]. Interaction of the C-terminal Grb2 SH3 domain with Grb2associated binding (Gab) scaffold protein family members couples RTKs to the PI3K/Akt survival pathway and to the Ras/MAPK cascade by an alternate route [14]. As such, the recruitment of Grb2 or Shc to RTKs has been shown to promote biologically redundant processes $[7,8,15,16]$. However, Shc proteins interact with diverse signaling molecules in addition to Grb2, thereby engage Grb2-independent pathways and biological functions [9-13,17-19].

Although the deregulation of RTKs is widely considered to be a major determinant in the progression of $\mathrm{CRC}$, the specific contributions of the proximal signaling molecules engaged by these receptors in CRC remain virtually unexplored. Herein, we report the exploitation of well-characterized adaptor-specific RTK docking variants derived from the oncogenic Met receptor, Tpr-Met $[8,9,15,16,20]$, with shRNA and pharmacological interference approaches to define, for the first time, the cancer properties associated with early neoplastic transformation of IECs, induced upon oncogenic mediated activation of either Grb2 or Shc signaling.

\section{Methods}

\section{Antibodies and reagents}

The Met polyclonal antibody, kindly provided by Dr. Morag Park (McGill University, Montreal, QC, Canada), was raised against an epitope in the $\mathrm{C}$-terminal region of human Met, distinct from those altered in the variants (Additional file 1) [8,21]. The Phospho-Tyr (p-Tyr100), phospho-Akt (Ser473), and phospho-Erk1/2 (p44/42MAPK, Thr202/Tyr204) antibodies were obtained from Cell Signaling Technology (Danvers, MA, USA). The pan-Shc and phospho-Tyr Shc (Tyr239/240) antibodies, that recognize the p66, p52, and p46 isoforms of ShcA, and the Erk2 antibody were obtained from Santa Cruz Biotechnology (Santa Cruz, CA, USA). The $\alpha$-tubulin and $\beta$-actin antibodies were from Sigma-Aldrich Canada Ltd (Oakville, ON, Canada). The Grb2 and E-cadherin antibodies were purchased from BD Transduction Labs (Lexington, KY, USA). The MEK1/2 and PI3K inhibitors, U0126 and LY294002, were purchased from Cell Signaling Technology, while the MEK1/2 inhibitors AZD6244 and PD184352 were obtained from Selleck Chemicals (Houston, TX, USA). 


\section{Grb2- and Shc-specific docking Tpr-Met variants and shRNAs}

As depicted in Additional file 1, the RTK-derived docking oncoproteins consist of an oncogenic form of the Met receptor, Tpr-Met, in which the multi-substrate binding region is replaced with a motif selective for the recruitment of a single signaling protein, found in other RTKs [8]. The Grb2-specific Tpr-Met variant (TM-Grb2) contains the Grb2 binding site derived from EGFR. Docking variants specific for the recruitment of Shc include either the high affinity Shc binding motif from the TrkA receptor (TM-Shc1), or the lower affinity motif from EGFR (TM-Shc2). The generation of these specific docking TprMet variants, and their insertion into the pLXSN retroviral expression vector were previously described [8]. For stable silencing of Grb2 and Shc in cells, a short hairpin RNA (shRNA) lentiviral vector-based approach was used. The design of the pLenti6-U6 construct for the stable transduction of shRNAs and the blasticidin $S$ resistance gene has been described previously [22]. Clontech shRNA Sequence Designer tool was used to create an shRNA containing nucleotide sequences that target rat Grb2 mRNA [23], the three ShcA isoforms [24], or a non-targeting control sequence [shGrb2 (NM_030846): 5'-GATGTACAGCACTT CAAGGTG-3'; shShc (NM_053517): 5' -CTACTTGGTT CGGTACATGGG-3'; shCTRL: 5'-GCTTTCCCGTCACG CGTACCT-3'].

\section{Cell culture}

Normal rat intestinal epithelial crypt cells, IEC-6, provided by Dr. A. Quaroni (Cornell University, Ithaca, NY), were maintained in DMEM (Wisent, St-Bruno, QC, Canada) containing $10 \%$ fetal bovine serum (FBS, Life Technologies, Burlington, ON, Canada) and $50 \mu \mathrm{g} / \mathrm{mL}$ gentamicin (Wisent). The IEC-6 cells were validated as nontransformed, and displaying normal features including an epithelioid morphology with sparse microvilli and Ecadherin cell-cell interactions, and a rate of cell division estimated by growth curve analysis that is typical of normal undifferentiated IECs $[5,22,25]$. Stable populations of IEC-6 cells expressing TM-Grb2, -Shc1, or -Shc2 (TMGrb2-IEC-6, TM-Shc1-IEC-6, and TM-Shc2-IEC-6 cells, respectively) were expanded, following retroviral infection, from a pool of at least 50 neomycin-resistant colonies, as described for the generation of IEC- 6 cells transformed with unmodified Tpr-Met (Tpr-Met-IEC-6 cells) [5]. For each experiment, populations of TM-Grb2-IEC-6, TMShc1-IEC-6, or TM-Shc2-IEC-6 cells were compared with the previously characterized sham-infected IEC-6 (Control-IEC-6) and Tpr-Met-IEC-6 cells [5], each having been passaged a comparable number of times (11-25 \pm 2 ). The binding specificity of these Tpr-Met variants was extensively validated in earlier studies $[8,9,15,16,20,26]$, and further confirmed in IEC-6 cells (Additional file 1). Stable knockdown of Grb2 or Shc expression in Tpr-Met-IEC-6 cells was achieved by lentiviral-mediated transduction of appropriate shRNAs. Production of replication-deficient lentiviruses in HEK 293 T cells and infection of Tpr-MetIEC-6 cells were performed as previously described [22]. Stable populations of Tpr-Met-IEC-6 cells expressing the shRNA against Grb2 or ShcA (TM-shGrb2 or TM-shShc cells) were selected, and thereafter maintained with blasticidin $\mathrm{S} \mathrm{HCl}(5 \mu \mathrm{g} / \mathrm{mL})$. A control Tpr-Met-IEC-6 cell population expressing a non-targeting shRNA was likewise generated (TM-shCTRL).

\section{Immunoprecipitation and immunoblotting}

Total cell lysate (TCL) preparation, SDS-PAGE, immunoprecipitation (IP), and immunoblot (IB) analysis methods have previously been described [8,9]. Primary antibodies were used at a concentration of 1:1000, with the exception of Akt and P-Akt (1:500), Erk2 (1:5000), P-Erk (1:2500), E-cadherin (1:5000), and $\alpha$-tubulin and $\beta$-actin (1:10000). Secondary antibodies were used at a concentration of 1:10000. Proteins were visualized by enhanced chemiluminescence (ECL, GE Healthcare, Baie d'Urfé, QC, Canada). Unless otherwise indicated, biochemical analyses were performed at least three times with independent lysate preparations from cells that had been serum-starved overnight.

\section{Semi-quantitative and quantitative RT-PCR}

Total RNA from serum-starved cells was extracted using TRIzol (Life Technologies) or RiboZol ${ }^{\mathrm{TM}}$ RNA Extraction Reagent (Amresco, Solon, OH), following the manufacturer's protocols. The RNA integrity was assessed with an Agilent 2100 Bioanalyzer (Agilent Technologies, Santa Clara, CA) and quantitation was performed using a Nanodrop spectrometer (Thermo Fisher). Reverse transcription was performed on DNase I-treated RNA (Amplification grade, Life Technologies) with Omniscript Reverse Transcriptase (Qiagen). Semi-quantitative PCR reactions were carried out using TOPTaq (Qiagen), according to the manufacturer's protocol. Resulting PCR products were then analyzed on a 2\% agarose gel. Quantitative real-time PCR analyses were performed by the RNomics Platform at the Université de Sherbrooke (Sherbrooke, QC, Canada). The sequence of the primers used is listed in Additional file 2 .

Cell-count, focus formation, soft agar growth, and anoikis assays

For cell-count assays, cells were seeded at a density of $2.5 \times 10^{4} /$ well in 6-well plates, and then counted daily. For focus formation assays, 200 cells of the experimental populations were seeded in each well of 6-well plates, with $5 \times 10^{5}$ parental IEC-6 cells forming a monolayer in each. After 10-15 days, the foci were photographed, fixed with $10 \%$ formalin buffer and stained with Giemsa 
for counting. Soft agar growth assays were conducted with 5000 cells per well, embedded in Noble Agar (Difco, BD Transduction Labs, Lexington, KY, USA). Colonies present after approximately two weeks were photographed and counted. For anoikis assays, cells were seeded in serum-free DMEM (or Opti-MEM) at a density of $1.25 \times 10^{5}$ cells/well in 24-well plates that were pre-coated (or not) with polyHEMA [poly-(2-hydroxyethyl methacrylate); Sigma]. After 18 hours, cell viability was determined by XTT assays [27]. The proportion of viable cells in polyHEMA-coated wells (suspension), relative to those seeded in non-coated wells (adherent), was calculated. Growth curves and bar graphs were generated using Prism v6.0c (GraphPad software, San Diego, CA, USA). Unless otherwise indicated, results are expressed as the mean \pm S.E.M. from three independent experiments, each performed in triplicate. Statistical significance was determined by ANOVA analysis (" indicates a p-value $<0.05$; ***, p < 0.01; ***;, $\mathrm{p}<0.001$; and $\left.{ }^{* * * * * *}, \mathrm{p}<0.0001\right)$.

\section{Ethics statement}

The research carried out did not involve any human subjects.

\section{Results}

Oncogenic engagement of Grb2 or Shc signaling promotes morphological transformation in normal IECs and reduces $\mathrm{E}$-cadherin expression

In contrast with many other RTKs, the ability of the Met receptor to recruit signaling proteins, and thus its biological activities, is dependent on two phospho-Tyr residues located within its C-terminus (Y1349/Y1356 in Met; Y482/Y489 in Tpr-Met [28-30]). This unique characteristic has been exploited to generate Met receptor variants capable of binding exclusively to a single RTKproximal signaling protein [8]. These well-characterized docking-specific Met variants consist of the cytosolic oncogenic form of the Met receptor, Tpr-Met, in which the multi-substrate binding region has been replaced with a motif selective for the recruitment of a single signaling protein, found in other RTKs (Additional file 1 and [8]). To determine whether the selective oncogenic engagement of either the Grb2 or the Shc adaptor protein was sufficient to induce transformation of IECs, we generated populations of IEC-6 cells [25] expressing Tpr-Met variants that specifically bind to either the Grb2 (TM-Grb2-IEC-6 cells) or Shc (TM-Shc1-IEC-6 and TM-Shc2-IEC-6 cells, respectively) adaptor proteins, through retroviral infection. For each experiment, these cells were compared with the previously characterized untransformed sham-infected IEC-6 (Control-IEC-6) cells or those transformed by unmodified Tpr-Met (TprMet-IEC-6) [5].
TM-Grb2-IEC-6, TM-Shc1-IEC-6, and TM-Shc2-IEC-6 cells were morphologically transformed to a similar extent relative to Control-IEC-6 cells, which grew in colonies and displayed typical normal epithelioid morphology (Figure 1A). Morphological changes induced in the TM-Grb2-IEC-6, TM-Shc1-IEC-6, and TM-Shc2-IEC-6 cells include an apparent breakdown of cell-cell contacts, cell dispersal, the acquisition of a fibroblast-like spindle-shaped morphology, and a more refractile appearance than the Control-IEC-6 cells. Cells expressing the Grb2 and Shc docking-specific oncoproteins also displayed many cell membrane protrusions typical of lamellipodia and invadopodia-like structures. The Tpr-Met variants exhibited comparable levels of Tyr phosphorylation in IEC-6 cells, relative to their expression levels (Figure 1A). They also demonstrated the predicted binding selectivity $[8,9,15,16,20]$ (Additional file 1 ).

Since such morphological changes in epithelial cells are typically associated with down-regulation of Ecadherin, immunoblot (IB) analysis of the E-cadherin protein levels were performed [31]. Consistent with the previous characterization of Tpr-Met-IEC-6 cells [5], also presented herein, oncogenic activation of Grb2- and especially Shc-specific signals led to a dramatic decrease in E-cadherin protein levels relative to the Control-IEC6 cells (Figure 1B). Likewise, a marked reduction in Ecadherin (Cdh1) mRNA levels was observed in these cells, as determined by semi-quantitative and quantitative real-time RT-PCR analyses (Figure $1 \mathrm{C}$ and D). Analysis of the expression profiles of E-cadherin transcriptional repressors in these IECs suggests that a combined upregulation of Snail2, Twist1, or Twist2, but not of Snail1 or Zeb1, may partly account for the E-cadherin repression induced by oncogenic Met-dependent signaling, including that one driven by Grb2 and Shc signals (Additional file 2). Overall, these results demonstrate that oncogenic activation of Grb2- and Shc-dependent signaling pathways, such as those activated by Tpr-Met, is sufficient to induce an epithelial-mesenchymal morphological-like transformation in normal IECs.

\section{Oncogenic engagement of Grb2 or Shc signaling enhances cell growth and loss of contact inhibition in IECs}

We next tested the oncogenic growth characteristics of IEC- 6 cells transformed by the Tpr-Met variants. First, cell-counting assays were performed to determine the growth rate of each cell population. The TM-Grb2-IEC6, TM-Shc1-IEC-6, and TM-Shc2-IEC-6 cells displayed more rapid growth than Control-IEC-6 cells, albeit to a lesser extent than Tpr-Met-IEC-6 cells (Figure 2A). Notably, TM-Shc1-IEC-6 cells exhibited accelerated growth relative to TM-Grb2-IEC-6 and TM-Shc2-IEC-6 cells, between which the doubling time did not differ significantly. The enhanced growth promoting activity of the TM-Shc1 relative to the TM-Shc2 correlates with the 
A
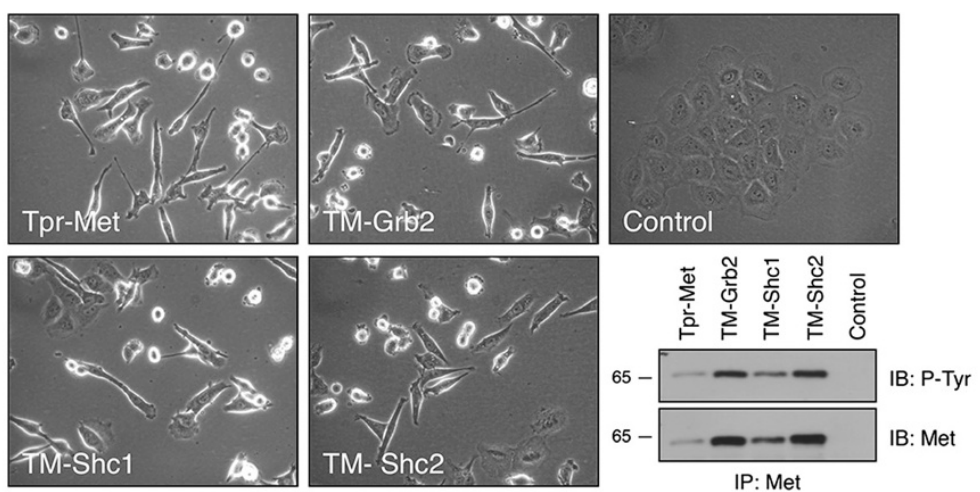

B

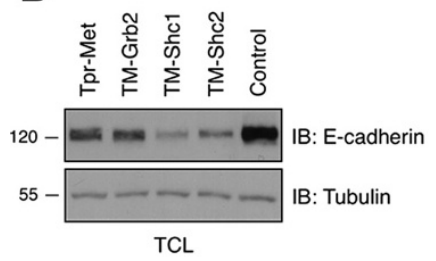

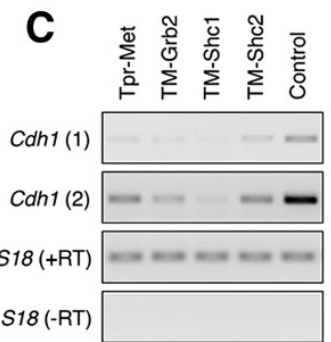

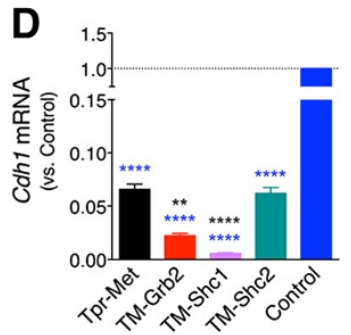

Figure 1 TM-Grb2, TM-Shc1 and TM-Shc2 oncoproteins promote morphological transformation and E-cadherin down-regulation in IEC-6 cells. (A) Photographs show the typical morphology of IEC-6 cells expressing, or not (Control), the docking-specific TM-Grb2, TM-Shc1 or TM-Shc2, or the oncogenic Met receptor, Tpr-Met. Expression and phosphorylation levels of these oncoproteins in IEC-6 cell lysates were assessed by immunoblot (IB) analyses following immunoprecipitation (IP) with a Met antibody. (B) E-cadherin protein levels were determined by IB analyses of total cell lysate (TCL) prepared from the indicated serum-starved cells. Tubulin protein levels provide a loading control. (C) E-cadherin mRNA expression (Cdh1) was evaluated by semi-quantitative RT-PCR assays performed with total RNA prepared from the indicated serum-starved cells. The analyses were carried out with two sets of primers designed to amplify distinct regions of the rat Cdh1 mRNA. The mRNA encoding for the S18 ribosomal protein is shown as a loading control. Parallel PCR reactions without the RT enzyme indicate that the amplified products did not arise from genomic DNA contamination. (D) Relative mRNA expression levels of Cdh1 were analyzed by quantitative real-time RT-PCR. These assays were carried out with the same RNA samples and sets of Cdh1 primers. The bar graph shows the mean \pm S.E.M. fold-change of Cdh1 mRNA levels relative to Control-IEC-6 cells. The values are from three independent sample sets run in duplicate, normalized to TATA-binding protein (TBP), pumilio RNA-binding family member 1 (Pum 1) and ribosomal protein L19 (Rp/19) expression. The primer sequences are listed in Additional file 2.

affinity of their respective Shc binding sites [8]. Typical of untransformed cells, IEC-6 cells ceased proliferation upon the establishment of cell-cell contacts [5,25]. As such, Control-IEC-6 cells formed a monolayer of well-organized epithelial cells upon reaching confluence (Figure 2B). In sharp contrast, each of the oncogenic transformed IEC-6 cell populations appeared highly disorganized and grew in multiple layers at confluence (Figure 2B). Thus, oncogenic specific activation of Grb2- or Shc-dependent signals permits IECs to bypass contact inhibition of growth. To validate this in a quantitative manner, focus formation assays were performed. As expected [5], Control-IEC-6 cells failed to form foci, whereas TM-Grb2-IEC-6, TM-Shc1IEC-6, and TM-Shc2-IEC-6 cells displayed strong focusforming capacities, though less than that of Tpr-Met-IEC6 cells (Figure 2C and D). The number and size of foci formed by the TM-Shc1-IEC-6 cells were markedly greater than those of the TM-Grb2-IEC-6 or TM-Shc2IEC-6 cells (Figure 2C and D), likely reflecting their accelerated growth rate (Figure 2A). These results indicate that the oncogenic engagement of Grb2- and Shc-dependent signals is sufficient to relieve contact inhibition of growth in IECs.

\section{Oncogenic engagement of Grb2 and Shc signaling induces anchorage-independent growth and anoikis resistance in IECs}

We next verified whether the oncogenic activation of Grb2- or Shc-dependent signals is sufficient to confer to non-transformed IEC-6 cells the capacity to grow in the absence of anchorage to the extra-cellular matrix (ECM), by performing soft agar growth assays. Consistent with previous findings [5], Control-IEC-6 cells failed to grow in soft agar whereas Tpr-Met-IEC-6 cells grew efficiently, forming numerous large colonies (Figure $3 \mathrm{~A}-\mathrm{C}$ ). TMGrb2-IEC-6, TM-Shc1-IEC-6, and TM-Shc2-IEC-6 cells also formed colonies in soft agar, but with lower efficiencies. While the three IEC-6 cell populations expressing docking-specific Tpr-Met variants formed similar numbers of colonies (Figure 3A), those produced by the TMShc1-IEC-6 cells were larger and displayed a different morphology from those produced by the TM-Shc2-IEC-6 

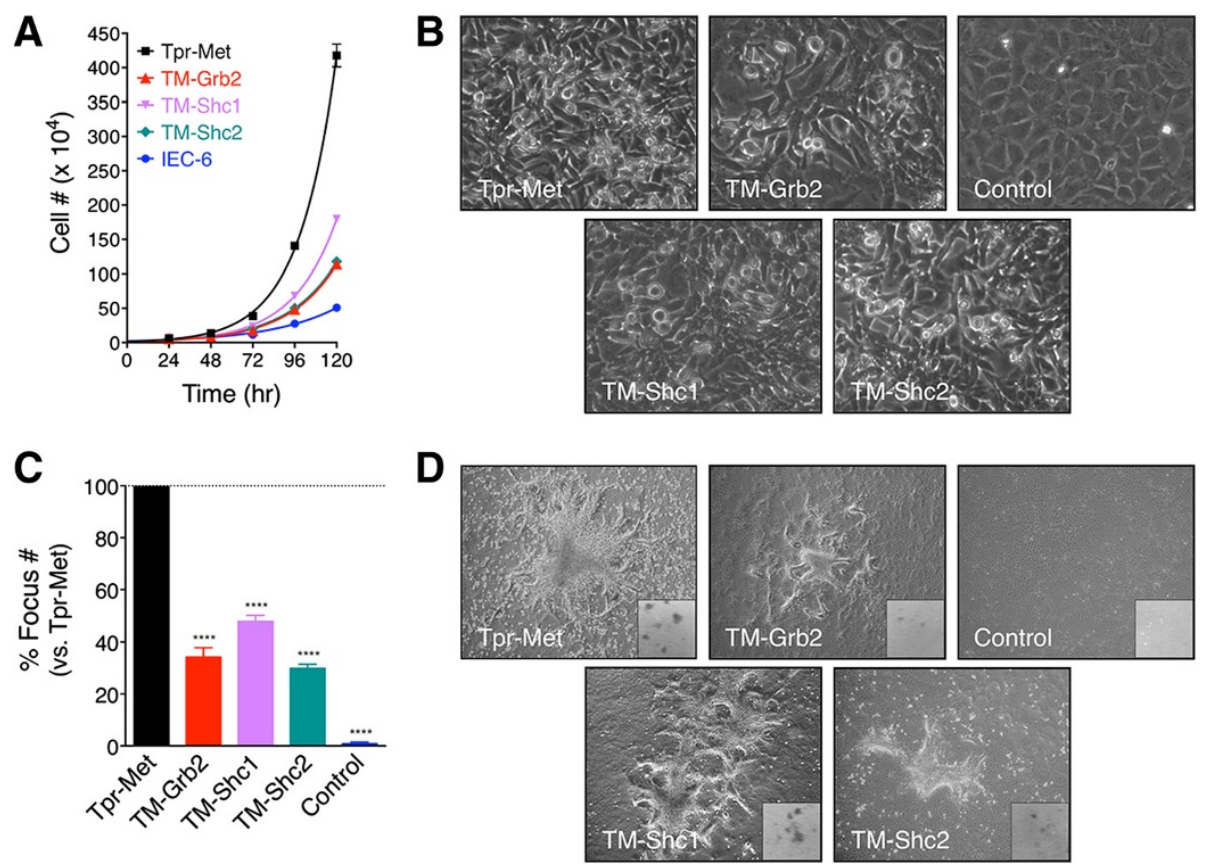

Figure 2 TM-Grb2, TM-Shc1 and TM-Shc2 oncoproteins elicit cell growth and loss of contact inhibition of growth in IEC-6 cells.

(A) Representative growth curves of IEC-6 cells expressing, or not (Control), the indicated Tpr-Met-derived oncoproteins. The doubling times calculated in hours, from 3 independent experiments performed in triplicate, are for Tpr-Met-IEC-6: 15.4 \pm 0.3; TM-Grb2-IEC-6: 21.5 \pm 0.6; TM-Shc1-IEC-6: 18.3 \pm 0.5; TM-Shc2-IEC-6: $20.9 \pm 0.7$ and Control-IEC-6: $29.5 \pm$ 1.9. (B) Photographs show typical morphology of the cells cultured at high density in the presence of serum. (C) Focus formation assays were performed with the indicated IEC-6 cell populations. The bar graph shows the average number of foci over $\sim 10$ days counted on stained plates in 3 independent experiments performed in triplicate. Values are expressed as percentage foci \pm S.E.M. of those formed by Tpr-Met-IEC-6 cells. (D) Photographs show representative morphology of the foci formed prior to formalin fixation and after Giemsa staining (small insets).

and TM-Grb2-IEC-6 cells (Figure 3B and C). Colonies formed by the TM-Shc1-IEC- 6 cells were composed mainly of loosely associated cells with apparently limited cell-cell contacts, similar to Tpr-Met-IEC-6 colonies (Figure 3B). By contrast, colonies produced by the TM-Grb2-IEC-6 or TM-Shc2-IEC-6 cells were compact and composed of tightly associated cells (Figure 3B).

Growth in soft agar reflects not only the capacity of cells to proliferate in the absence of ECM attachment, but also to avoid anoikis, a form of apoptosis induced upon loss of matrix attachment [32]. Anoikis assays were performed by monitoring the viability of cells seeded in the absence of serum under adherent and suspension conditions. As expected for normal IECs [33,34], ControlIEC-6 cells displayed anoikis sensitivity under suspension culture conditions (Figure 3D). In contrast, IEC-6 cells transformed by either Tpr-Met, or the Grb2 or Shc docking-specific oncoproteins, displayed potent resistance to anoikis, with more than half surviving under non-adherent conditions. Likewise, the viability of these transformed cells was significantly higher than that of Control-IEC-6 cells when seeded in the absence of serum and under adherent conditions (Figure 3E). Overall, these results indicate that the oncogenic engagement of signals downstream of Grb2 or Shc is sufficient to alleviate the anchorage-dependence of growth, and to reduce sensitivity to growth factor deprivation and to anoikis in IECs.

\section{Silencing of Grb2 impairs Tpr-Met-induced morphological transformation and anoikis resistance in IECs, but reduced expression of Shc decreases cell growth}

The above results with the docking-specific Tpr-Metderived variants established that the oncogenic activation of either Grb2 or Shc signaling pathways was each sufficient to promote transformation of IECs, conferring upon them aberrant growth characteristics and resistance to anoikis. We next sought to determine whether signaling pathways downstream of these adaptor proteins were required for the oncogenic potential of Met in IECs. The impact of silencing the expression of Grb2 or Shc on the features of the Tpr-Met-IEC-6 cells was evaluated. Stable populations of Tpr-Met-IEC-6 cells displaying marked and selective knockdown of Grb2 (TMshGrb2) or Shc (TM-shShc) were generated using shRNAs. As demonstrated by IB analyses (Figure 4A), Grb2 and Shc (all ShcA isoforms) protein levels were selectively reduced by more than $60 \%$ in TM-shGrb2 and TM-shShc cell 


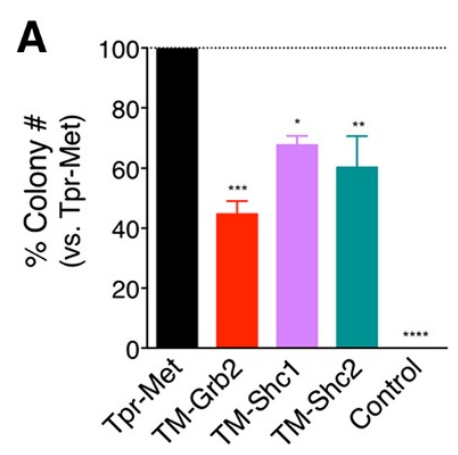

B
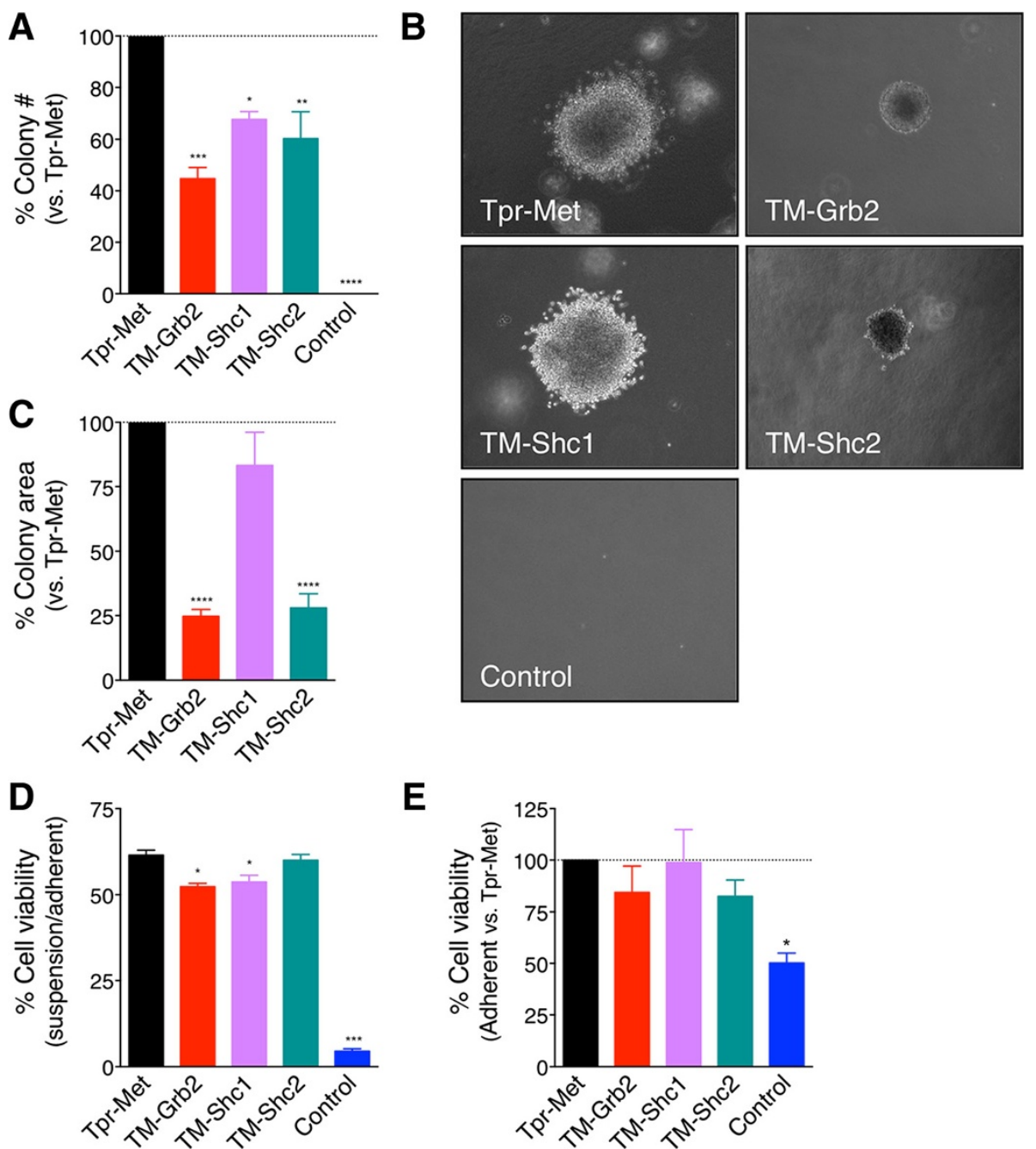

E
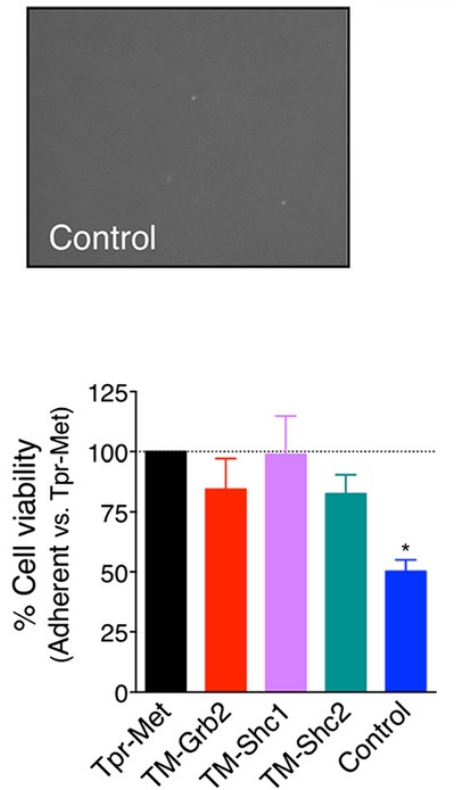

Figure 3 TM-Grb2, TM-Shc1 and TM-Shc2 oncoproteins induce anchorage-independent growth and anoikis resistance in IEC-6 cells. (A) The ability of the indicated IEC-6 cell populations to grow in an anchorage-independent manner was tested in soft agar assays. The bar graph represents the average number of colonies formed in soft agar, expressed as percentage \pm S.E.M. of those produced by Tpr-Met-IEC-6 cells, from 3 independent experiments performed in triplicate. Tpr-Met-IEC-6 cells, when seeded at a density of 5000 cells in a 6-well plate, were producing an average of 300-500 colonies after 10 days. (B) Photographs depict typical morphology of the colonies formed in soft agar. (C) The bar graph represents the average size of colonies formed in soft agar, expressed as percentage \pm S.E.M. of those produced by Tpr-Met-IEC-6 cells, from 3 independent experiments performed in triplicate. (D) Anoikis sensitivity of these IEC-6 cell populations was tested. Cell viability was measured by XTT assays 18 hours after seeding the cells in suspension or adherent conditions. The bar graph shows in percentage the mean \pm S.E.M. value of viable cells grown in suspension relative to the adherent ones, calculated from 4 independent experiments performed in triplicate. (E) Cell viability in adherent condition, expressed as the percentage mean \pm S.E.M. relative to Tpr-Met, is shown.

populations, respectively, compared to Tpr-Met-IEC-6 cells expressing a non-targeting shRNA (TM-shCTRL). Protein levels of Tpr-Met and actin remained equivalent amongst all these cell populations. Phase contrast microscopy revealed that the TM-shGrb2 cells exhibited a partial reversal of the transformed morphology, relative to TMshCTRL cells, characterized by a decrease in cell refractility and an increase in cell spreading (Figure 4B). In contrast, the TM-shShc cells maintained the transformed morphology, and even adopted a slightly more elongated and spindle-shaped appearance than the control TM-shCTRL cells. Concordant with these morphological changes, E-cadherin protein levels were enhanced in TM-shGrb2 cells and reduced in TM-shShc cells, when compared to TM-shCTRL cells (Figure 4C and D).

Growth and survival characteristics of these cells were then evaluated in cell-count and anoikis assays, respectively. While the TM-shGrb2 cells displayed similar growth capacity to TM-shCTRL cells, growth of the TM-shShc cells was observed to decrease in a time-dependent manner, reaching significant inhibition $(37.67 \pm 5.32 \%) 3$ days after seeding (Figure 4E). The TM-shGrb2 cells displayed 


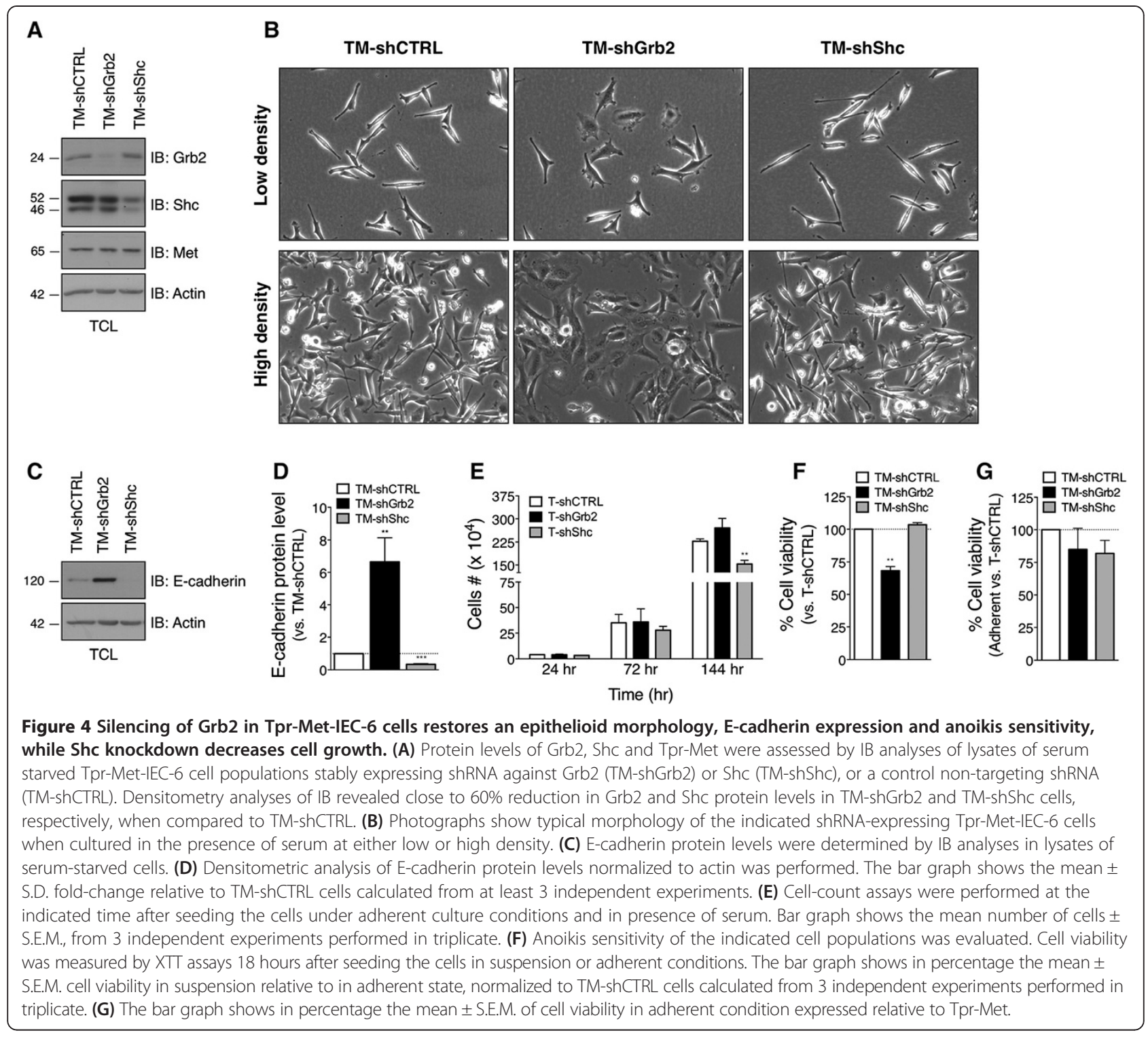

enhanced anoikis sensitivity when compared to the TMshCTRL and TM-shShc cells, between which no difference in survival in suspension was observed (Figure 4F). As shown in Figure 4G, no significant difference in cell viability was observed between the TM-shGrb2, TM-shShc, and TM-shCTRL cells 18 hours following seeding in the absence of serum under adherent conditions (Figure 4G). Together, these results suggest that signals downstream of Grb2 and Shc proteins are required for non-overlapping functions promoted by the oncogenic Met receptor in IECs.

\section{MEK, but not PI3K inhibitors reduce IEC transformation} promoted by the oncogenic engagement of Met, Grb2, or Shc signals

The Grb2 and Shc adaptor proteins are known to couple RTKs, such as the Met receptor, to the Ras/MAPK and
PI3K/Akt signaling pathways [28-30]. The Ras/MAPK and PI3K/Akt pathways are important regulators of RTK-mediated epithelial cell transformation, but their actions are cell type-specific [31]. To define the role of these signaling pathways in IEC transformation, we first compared their activation status in IEC-6 cells transformed by the Tpr-Met, TM-Grb2, TM-Shc1, and TM-Shc2 oncoproteins, to that one in non-transformed Control-IEC-6 cells. The phosphorylation/activation levels of the downstream effectors of MEK and PI3K, Erk1/2 and Akt, respectively, were assessed by IB analyses of lysates prepared from serum-starved IEC-6 cells. Phosphorylation levels of neither Erk1/2 nor Akt were elevated in Tpr-Met-IEC-6, TM-Grb2-IEC-6, TM-Shc1-IEC-6, or TM-Shc2-IEC-6 cells, relative to Control-IEC-6 cells (Figure 5A). Both Erk2 and Akt protein levels were comparable in all IEC-6 cell 


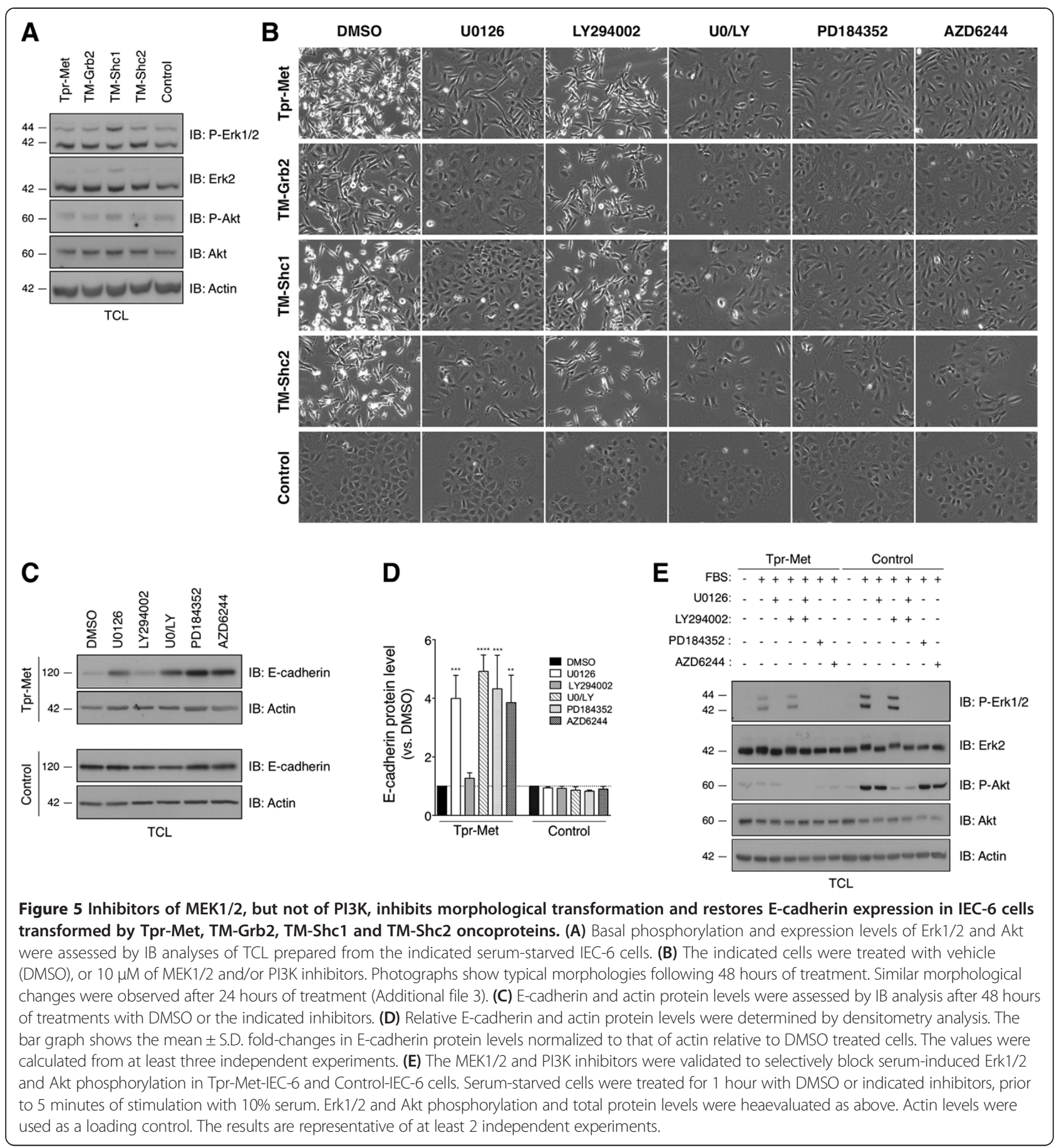

populations. A similar trend of Erk1/2 and Akt phosphorylation was observed in cells maintained in the presence of serum (data not shown). The lack of evidence for Erk1/2 and Akt activation in IEC-6 cells stably expressing the constitutively activated form of the Met receptor, or the Grb2 and Shc docking-specific oncoproteins, is consistent with both the Ras/MAPK and PI3K/Akt pathways being subject to negative feedback mechanisms [35]. It cannot be explained as merely a cell type-specific event, since similarly stable expression of these oncoproteins in fibroblasts failed to promote Erk1/2 or Akt activation [36 and unpublished observation].

We next investigated whether, even at the low levels observed, MEK or PI3K activities were implicated in the induction of transformation features in IEC-6 cells by the Tpr-Met, TM-Grb2, TM-Shc1, or TM-Shc2 oncoproteins. Cells were treated with vehicle (DMSO), $10 \mu \mathrm{M}$ U0126 (a MEK1/2 inhibitor), $10 \mu \mathrm{M}$ LY294002 (a PI3K 
inhibitor), or a combination of both inhibitors, and their morphology was examined by phase contrast microscopy, following 24 (Additional file 3) and 48 hours of treatment (Figure 5B). Neither individual inhibitor treatment, nor the combination, had an obvious effect on the morphology of the Control-IEC-6 cells. Interestingly, the MEK1/2 inhibitor, but not the PI3K inhibitor, induced a potent reversion of the transformed morphological features of the Tpr-Met-IEC-6, TM-Grb2-IEC-6, TM-Shc1IEC-6, and TM-Shc2-IEC-6 cells, observed within 24 hours of treatment (Additional file 3 ) and more striking in appearance after 48 hours (Figure 5B). In the presence of U0126, the MEK1/2 inhibitor, either alone or in combination with the PI3K inhibitor, the formerly transformed Tpr-IEC-6 cells progressively lost their fibroblast-like spindle-shaped morphology, adopted a flatter cobblestone-like appearance, reformed apparent cell-cell contacts and grew again in colonies; much like the non-transformed Control-IEC-6 cells.

Concordant with this restoration of epithelioid-like morphological features in IEC-6 cells transformed by the oncogenic Tpr-Met and its derived variants, treatment with U0126 also induced an increase in E-cadherin protein levels (Figure 5C and D, and Additional file 3). By contrast, none of the inhibitor treatments affected E-cadherin protein levels in the Control-IEC-6 cells (Figure 5C and D). Notably, reversion of the transformed phenotype and Ecadherin up-regulation were also promoted in transformed IEC-6 cell populations by treatment with $10 \mu \mathrm{M}$ AZD6244 or PD184352, two additional pharmacological inhibitors of MEK1/2 (Figure $5 \mathrm{~B}$ and $\mathrm{C}$, and Additional file 3). Furthermore, these observations could not be attributed to the cytosolic localization of the Tpr-Met oncoprotein, since both the morphological transformation and the E-cadherin down-regulation induced by a cell surfacelocalized active chimeric colony stimulating factor 1 (CSF)-Met receptor [37], were reverted in a similar manner upon the inhibition of MEK1/2 activity, but not of PI3K activity (Additional file 3).

Since Erk1/2 and Akt activities remained at basal levels in transformed IEC- 6 cell populations, the efficacy of these pharmacological inhibitors was evaluated by testing their ability to suppress serum-induced Erk1/2 and Akt phosphorylation. Serum-starved Tpr-Met and control IEC-6 cell populations were treated for 1 hour with DMSO or inhibitors, followed by 5 minutes of stimulation with $10 \%$ serum. A robust phosphorylation of Erk $1 / 2$ and Akt proteins was seen upon serum stimulation of Control-IEC-6 cells (Figure 5E). In sharp contrast, although the levels of Erk2 and Akt proteins were equivalent for each cell population, serum-induced Erk $1 / 2$ and Akt activation were severely attenuated in the Tpr-Met-IEC-6 cells (Figure 5E). This further substantiates the conclusion that sustained activation of
Met signaling pathways, such as those downstream of Grb2 and Shc, can activate negative feedback control of both the Erk1/2 and Akt pathways in IECs. Importantly, the MEK1/2 and PI3K inhibitors were confirmed to efficiently suppress serum-induced Erk1/2 and Akt phosphorylation, respectively (Figure 5E). Although the potential off-target effects of these inhibitors cannot be excluded in these experiments, our results suggest that the morphological transformation induced by the oncogenic Met receptor, and driven by the constitutive activation of Grb2 and Shc signals in IECs, relies, at least in part, on the activation of the Ras/MAPK pathway, but not on PI3K signaling.

\section{The growth promoting effect of oncogenic Met in IECs is blocked by MEK inhibition, but anoikis sensitivity is restored by concomitant treatment with MEK and PI3K inhibitors}

We next investigated whether the growth capacity promoted by the oncogenic Met in IECs required MEK or PI3K activity. Cell-count assays were performed with Tpr-Met and Control-IEC-6 cells that were treated for 24 or 48 hours with vehicle, U0126 or LY294002 inhibitor, or a combination of both inhibitors. As anticipated, treatment with DMSO did not significantly impact cell growth, even after 48 hours. Treatment with LY294002 exerted similar inhibitory effects upon the growth of both the Tpr-Met-transformed and control IEC- 6 cells, reducing the number of cells by $44 \%$ and $36 \%$, respectively relative to DMSO-treated cells, after 48 hours (Figure 6A). In contrast, in the presence of U0126, the growth of TprMet-IEC-6 cells was significantly attenuated but not that of Control-IEC-6 cells (Figure 6A). Furthermore, while co-treatment with U0126 failed to potentiate the growth inhibiting effect of LY294002 in Control-IEC-6 cells, the growth of Tpr-Met-IEC-6 cells was further reduced in a time-dependent manner upon exposure to both inhibitors (Figure 6A).

The impact of inhibiting MEK1/2 or PI3K activity on the viability of Tpr-Met-IEC-6 cells in suspension was also evaluated. In these anoikis assays, vehicle or the indicated inhibitors were added when cells were seeded and cell viability was measured 24 and 48 hours later. Treatment with the PI3K inhibitor restored anoikis sensitivity to the Tpr-Met-IEC-6 cells in a time-dependent manner, reducing their viability by close to $45 \%$ relative to DMSO-treated cells after 48 hours (Figure 6B). The MEK1/2 inhibitor, on the other hand, did not substantially impact the viability of the Tpr-Met-IEC-6 cells grown in suspension. Nonetheless, U0126 treatment did elicit a marked synergistic effect on LY294002-induced anoikis, reducing Tpr-Met-IEC-6 cell viability to levels well below those seen upon treatment with the PI3K inhibitor alone (Figure 6B). These results suggest that Tpr- 

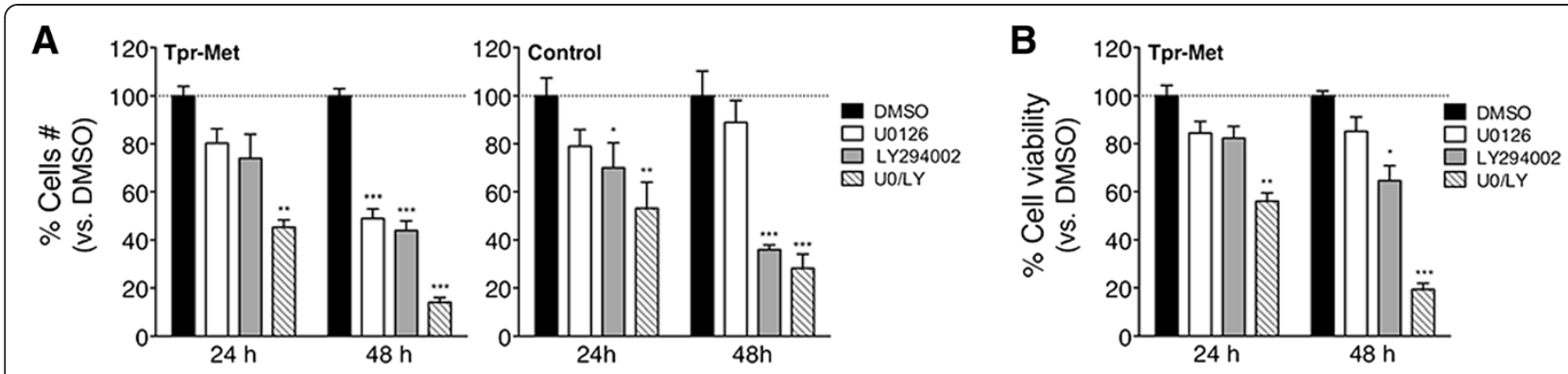

Figure 6 Tpr-Met-mediated enhanced growth in IECs is reduced by inactivation of MEK1/2, and resistance to anoikis is restored by dual inactivation of MEK1/2 and PI3K. (A) Cell-count assays were performed with Tpr-Met and Control-IEC-6 cells cultured under adherent conditions and in presence of serum, after 24 and 48 hours of treatment with vehicle (DMSO), $10 \mu M$ of the MEK1/2 or PI3K inhibitor, or a combination of both inhibitors. The bar graph shows as percentage the mean number of cells \pm S.E.M. relative to DMSO-treated cells. (B) Anoikis assays were conducted 24 and 48 hours after seeding Tpr-Met-IEC-6 cells in suspension, and concurrently in the presence of the vehicle or indicated inhibitors. The bar graph represents in percentage the mean value \pm S.E.M. of cell viability normalized to DMSO-treated cells, calculated from 3 independent experiments performed in triplicate.

Met-mediated growth promoting effects observed in IECs implicate MEK-dependent mechanisms, but that the anoikis resistance involves the integration of both MEK- and PI3K-dependent signaling pathways.

\section{Discussion}

As normal intestinal epithelial cells become cancerous, they gain the ability to grow aberrantly by evading normal growth-inhibiting and death signals, as well as the ability to invade tissue [38]. Experimental and clinical studies suggest that the deregulation of RTKs plays a critical role in the etiology and progression of human CRC [2-4]. These studies highlight the ability of RTKs to induce biological characteristics linked with tumorigenesis and metastatic progression $[1,38]$. However, the proximal signaling molecules recruited by RTKs have not yet been assigned individual contributions to the neoplastic transformation of normal IECs. In this study, Met-derived dockingspecific variants were used to define the cancer properties induced upon the RTK-mediated engagement of the Grb2 or Shc adaptor proteins in IECs. Our results show, for the first time in a non-transformed IEC model, that the sustained activation of signals downstream of either Grb2 or Shc alone is sufficient to promote morphological transformation, E-cadherin down-regulation, enhanced cell growth, loss of contact inhibition of growth, the acquisition of anchorage-independence of growth, and anoikis resistance (Figures 1, 2, 3). These oncogenic features are prerequisites for the progression of epithelial-derived cancers, favoring the survival and growth of cancerous cells in the matrix-poor, disorganized extracellular environments often found in primary tumors, and in systemic circulation, facilitating metastasis $[32,38]$. Thus, our results provide novel evidence for a causal role of RTK-linked Grb2 and Shc signaling pathways in important and common phenotypic features of neoplastic transformation of IECs and metastatic CRCs.
Expression of the cell adhesion molecule, E-cadherin, is typically depleted from cell-cell contacts in epithelial cancer cells, or even shut down altogether [31]. Cellular loss of E-cadherin leads to dissolution of adherens junctions and to a reduction in cell-cell contacts, facilitating migration and invasion, both of which are key processes for metastatic dissemination of epithelial tumor cells. Notably, an inverse correlation exists between E-cadherin levels in human CRC specimens and cancer grade, invasiveness of tumor phenotype, metastatic disease progression, and poor patient prognosis [39]. Multiple mechanisms have been identified that promote E-cadherin down-regulation in epithelial cells, in response to different stimuli and/or in different cell types. These include transcriptional silencing via deregulation of transcription factors (Snail, Twist, and Zeb) or promoter hyper-methylation, and internalization followed by subsequent lysosomal degradation mediated by post-translational modifications [31,40]. E-cadherin protein levels were further reduced in IEC-6 cells expressing the Shc docking-specific oncoproteins than those transformed by TM-Grb2 or Tpr-Met (Figure 1). Differential expression levels of these oncoproteins cannot fully account for this response, therefore suggesting that Grb2 and Shc might mediate E-cadherin down-regulation by distinct mechanisms. However, E-cadherin levels and an epithelial non-transformed typical morphology were restored upon pharmacological inhibition of MEK1/2 but not of PI3K, activities in IECs transformed by these oncoproteins (Figure 5 and Additional file 3). These findings suggest that the engagement of Grb2 and Shc, like Met, promotes these oncogenic features through shared signaling pathways. Furthermore, E-cadherin repression induced by oncogenic Met signaling pathways in IECs, like that driven by Grb2 and Shc, was associated with an up-regulation of the repressors of E-cadherin transcription Snail2, Twist1, or Twist2, but not of Snail1 or Zeb1 (Additional file 2). Future studies will be needed 
to define the shared and distinct mechanisms that result in E-cadherin down-regulation in IECs downstream of Grb2 or Shc. Nonetheless, our results suggest that these adaptor proteins are important integrators of signals leading to the neoplastic transformation and Ecadherin dysfunction in CRC harboring the deregulated Met receptor, and most likely other RTKs.

A role for deregulated RTKs in conferring anoikis resistance to IECs through cross-talk with cell adhesion receptors, is well-established [32]. While transforming growth factor- $\alpha$ (TGF- $\alpha)$ stimulation protects IECs from anoikis [41], CRC cells that express high levels of EGF/ TGF- $\alpha$ evade anoikis through autocrine stimulation of the EGFR [33]. However, the importance of Grb2 or Shc functions in anoikis resistance in IECs has not been addressed. Furthermore, of the very few investigations of the HGF/Met receptor axis in anoikis control and cancer, a single study has reported a key role for the Met receptor in CRC cells [42]. Activation of the Met receptor has been reported to prevent anoikis in human colon, ovarian, pancreatic, and head and neck carcinoma cell lines by mechanisms dependent on PI3K, but with varied requirement for MEK1/2 [42-45]. Herein, we have shown that while individual inhibition of PI3K activity, but not of MEK1/2, partially restored anoikis sensitivity in Tpr-MetIEC-6 cells, concurrent inhibition of these pathways exerted a synergistic effect (Figure 6). Notably, anoikis resistance driven by the oncogenic Met receptor in IECs is partly dependent on Grb2 functions, whereas Shc functions appear dispensable (Figure 4). Our findings suggest a model whereby deregulation of Met might promote anoikis resistance in CRC cells, through the integration of both MEK and PI3K signaling pathways, and likely involving the engagement of Grb2. Collectively, our results provide novel evidence that signaling pathways engaged by deregulated RTKs in CRC, including those reliant on Grb2 or Shc, may represent important regulators of anoikis resistance in IECs, a process of outmost relevance in cancer metastasis.

We show that oncogenic Met receptor-dependent signals, like those activated downstream of Grb2 and Shc, trigger negative feedback upon the Ras/MAPK and PI3K/Akt pathways in IECs, restricting Erk and Akt activation (Figure 5 and Additional file 3). Although somewhat controversial, some studies suggest that Erk hyperactivation may only occur in a small subset of CRC tumors, and that Erk activity is more often elevated in adjacent normal tissue [46-48]. Also, Erk activity in human CRC tumors appears to be a poor predictor of activating $K-R A S$ mutation status and of the effectiveness of MEK inhibition [48-50]. We report the inhibition of the IEC transformation and E-cadherin down-regulation induced by each of our oncoproteins by inhibitors of MEK activity, but not of PI3K activity (Figure 5 and Additional file 3). Cell growth and anoikis resistance evoked by Tpr-Met, on the other hand, was blocked by concomitant treatment with MEK and PI3K inhibitors (Figure 6). Thus, our findings suggest that while growth factor stimulation is linked to the activation of the Ras/MAPK and PI3K/Akt pathways, in part through Grb2 and Shc, Erk or Akt activity levels in CRC may not reliably predict the extent of RTK deregulation, nor the sensitivity to therapies targeting them.

The Tpr-Met and the Grb2- and Shc-specific docking oncoproteins are all predicted to promote cancer features in IECs by engaging similar signaling pathways. Indeed, they share the ability to complex with the Gab1 scaffolding protein. While binding to TM-Grb2 and TM-Shc oncoproteins by Grb2-dependent mechanisms, Gab1 also interacts directly with the Met receptor $[8,20,51]$. Notably, Gab1 has been shown to be required for Erk and Akt activation, and many oncogenic functions downstream of Met, and the Grb2- and Shc-docking oncoproteins in fibroblast, MDCK epithelial, and Xenopus cell models $[20,28]$. Thus, it may be that Gab1 provides a platform for the integration of Ras/MAPK and PI3K/Akt positive and negative signals downstream of these oncoproteins and relevant to their oncogenic functions in IECs. However, Tpr-Met-IEC-6 cells were observed to display stronger transformed phenotypes than cells expressing the Grb2 or Shc-binding variants oncoproteins, for example in focus-formation and growth in soft agar (Figures 2 and 3). This suggests that Tpr-Met may activate pathways not engaged by the Tpr-Met Shc or Tpr-Met Grb2 oncoproteins. Furthermore, it is now acknowledged that Shc, by interacting with proteins other than Grb2 such as IQGAP1, Crk and Sgk269, can promote Grb2independent pathways and functions [13,17-19], underscoring the complexity of the cellular networks that these adaptor proteins can engage downstream of RTKs. It is therefore anticipated that the Grb2- and Shc-specific docking oncoproteins, and Tpr-Met may prove, upon further analyses, to mediate distinct signaling pathways, and therefore specific cancer processes in IECs.

Therapies targeting RTKs are recognized as a promising avenue for the treatment of cancer, but the clinical benefits observed with these agents have so far been modest. As typified by EGFR-targeted therapies for metastatic CRC (e.g.: panitumumab and cetuximab), this modest response is attributed to the innate and acquired proficiency of cancer cells to escape EGFR inhibition by engaging alternative oncogenic signals [2,3,52]. Multiple mechanisms of resistance have been proposed, including the manifest heterogeneity of RTKs being deregulated in CRC cells [52,53]. Notably, activation of the Met/HGF receptor axis is emerging as an important mechanism of resistance to drugs targeting oncogenic kinases in 
human cancers, including CRC, while concurrent inhibition of multiple RTKs in CRC cells seems to offer better therapeutic effects than targeting a specific RTK [53-60]. An alternative way to achieve similar outcomes might be offered by targeting RTK-proximal signaling effectors engaged by all, or at least several RTKs, particularly those regulating biological processes critical for the initiation and/or progression of CRCs. In this regard, we show that although oncogenic engagement of Grb2 or Shc triggers redundant cancer properties in IECs (Figures 1, 2, 3), these adaptor proteins were proven, through analysis of the impact of their silencing in Tpr-Met-transformed IECs, to be necessary for non-overlapping functions (Figure 4). The silencing of Shc in Tpr-Met-IEC-6 cells was demonstrated to partly reduce cell growth without impacting anoikis resistance, but slightly increasing transformation and E-cadherin down-regulation. These results indicate that the Met receptor has the intrinsic capacity to circumvent the loss of Shc functions by engaging alternative oncogenic signals, likely involving the adaptor proteins Grb2, Gab1, or others effectors. Conversely, inhibition of Grb2 functions restored normal non-transformed epithelial morphology, E-cadherin expression, and anoikis sensitivity in these same Mettransformed IECs. Incidentally, Grb2 SH2 domain-binding antagonists were shown in vitro to block HGF-induced migration and invasion in MDCK epithelial cells, metastasis formation of melanoma and prostate cancer cells in vivo, and the motility of human SW620 CRC cells in wound-healing in vitro assays [61-63]. Considering these observations, with our current findings, we suggest the targeting of Grb2 signaling in CRC, particularly in the context of deregulated Met, as a potentially effective therapeutic strategy to reduce CRC metastasis.

\section{Conclusions}

The design of novel CRC therapies is contingent on a better understanding of the mechanisms underlying the ability of deregulated RTKs to relay downstream signaling pathways that convey oncogenic properties in normal IECs. In this study, we provide evidence that Met-driven oncogenic activation of Grb2 or Shc signaling leads to the neoplastic transformation of normal IECs and induces multiple redundant hallmarks of cancer in these cells. Sustained engagement of Grb2 and Shc in IECs was also identified to evoke negative feedback control of the Ras/MAPK and PI3K/Akt pathways, limiting their degree of activation, however these pathways seem to remain critical to oncogenic functions. Notably, our data also illustrate the functional nonredundancy of Grb2 and Shc downstream of Met, and suggest that Grb2 might represent a promising target for the design of novel therapies for CRC harboring deregulated Met, and possibly other RTKs.

\section{Additional files} Additional file 1: TM-Grb2, TM-Shc1, and TM-Shc2 oncoproteins
display the expected docking specificity when expressed in IEC-6 cells.

Additional file 2: Oncogenic Met, Grb2, and Shc signaling pathways alter the expression of critical E-cadherin transcriptional repressors.

Additional file 3: IEC transformation induced by oncogenic Met, Grb2, and Shc signaling requires MEK but not PI3K, activity.

\section{Competing interests}

The authors declare that they have no competing interests.

\section{Authors' contributions}

VP contributed to the conception of the study, performed cell and molecular studies, and drafted the manuscript. ML carried out part of the anoikis and pharmacological studies. JB generated and carried out the initial characterization of the IEC populations expressing the Tpr-Met and docking-specific variants. PHV participated in drafting the manuscript. CS coordinated all aspects of the study and participated in the writing of the manuscript. All authors read and approved the final manuscript.

\section{Acknowledgements}

We are grateful to Dr. Morag Park for providing the Met antibody, and Tpr-Met and CSF-Met CDNAs; and to members of the CIHR digestive epithelium team for equipment and reagents. We also thank members of the Saucier laboratory, and Drs. Fiona Robinson and Alfredo Menendez for their helpful and critical comments on the manuscript. This work was supported by grants from the Canadian Institutes of Health Research (CIHR, MOP-106476) and the Natural Sciences and Engineering Research Council of Canada (NSERC-342061) awarded to CS. ML is a recipient of a studentship from the Centre de Recherche en Biologie des épithéliums (CRBé) de I'Université de Sherbrooke. CS is a Chercheur-Boursier du Fonds de la Recherche en Santé du Québec (FRSQ), and CS and PHV are Canadian Foundation for Innovation researchers, and members of the Centre de Recherche Clinique Étienne-Le Bel du Centre hospitalier universitaire de Sherbrooke, an FRSQ-funded research center.

Received: 8 November 2013 Accepted: 31 March 2014 Published: 4 April 2014

\section{References}

1. Lemmon MA, Schlessinger J: Cell signaling by receptor tyrosine kinases. Cell 2010, 141(7):1117-1134.

2. Saucier C, Rivard N: Epithelial cell signalling in metastatic colorectal cancer. In Metastasis of Colon Cancer, Volume 14. Edited by Huot J, Beauchemin N. Dordrecht, Heidelberg, London, New York: Springer Netherlands; 2010:205-241.

3. Efferth T: Signal transduction pathways of the epidermal growth factor receptor in colorectal cancer and their inhibition by small molecules. Curr Med Chem 2012, 19(33):5735-5744.

4. Samame Perez-Vargas JC, Biondani P, Maggi C, Gariboldi M, Gloghini A, Inno A, Volpi CC, Gualeni AV, di Bartolomeo M, de Braud F, Castano A, Bossi I, Pietrantonio F: Role of cMET in the development and progression of colorectal cancer. Int J Mol Sci 2013, 14(9):18056-18077.

5. Bernier J, Chababi W, Pomerleau V, Saucier C: Oncogenic engagement of the Met receptor is sufficient to evoke angiogenic, tumorigenic, and metastatic activities in rat intestinal epithelial cells. Am J Physiol Gastrointest Liver Physiol 2010, 299(3):G677-G686.

6. Boon EM, Kovarikova M, Derksen PW, van der Neut R: MET signalling in primary colon epithelial cells leads to increased transformation irrespective of aberrant Wnt signalling. Br J Cancer 2005, 92(6):1078-1083.

7. Dankort DL, Wang Z, Blackmore V, Moran MF, Muller WJ: Distinct tyrosine autophosphorylation sites negatively and positively modulate neu-mediated transformation. Mol Cell Biol 1997, 17(9):5410-5425.

8. Saucier C, Papavasiliou V, Palazzo A, Naujokas MA, Kremer R, Park M: Use of signal specific receptor tyrosine kinase oncoproteins reveals that pathways downstream from Grb2 or Shc are sufficient for cell transformation and metastasis. Oncogene 2002, 21(12):1800-1811. 
9. Saucier C, Khoury H, Lai KM, Peschard P, Dankort D, Naujokas MA, Holash J, Yancopoulos GD, Muller WJ, Pawson T, Park M: The Shc adaptor protein is critical for VEGF induction by Met/HGF and ErbB2 receptors and for early onset of tumor angiogenesis. Proc Natl Acad Sci U S A 2004, 101(8):2345-2350.

10. Oku S, van der Meulen T, Copp J, Glenn G, van der Geer P: Engineering NGF receptors to bind Grb2 directly uncovers differences in signaling ability between Grb2- and ShcA-binding sites. FEBS Lett 2012, 586(20):3658-3664.

11. Lucs AV, Muller WJ, Muthuswamy SK: Shc is required for ErbB2-induced inhibition of apoptosis but is dispensable for cell proliferation and disruption of cell polarity. Oncogene 2010, 29(2):174-187.

12. Dankort D, Maslikowski B, Warner N, Kanno N, Kim H, Wang Z, Moran MF, Oshima RG, Cardiff RD, Muller WJ: Grb2 and Shc adapter proteins play distinct roles in Neu (ErbB-2)-induced mammary tumorigenesis: implications for human breast cancer. Mol Cell Biol 2001, 21(5):1540-1551.

13. Wills MK, Jones $\mathrm{N}$ : Teaching an old dogma new tricks: twenty years of Shc adaptor signalling. Biochem J 2012, 447(1):1-16.

14. Gu H, Neel BG: The "Gab" in signal transduction. Trends Cell Biol 2003, 13(3):122-130.

15. Mood K, Saucier C, Ishimura A, Bong YS, Lee HS, Park M, Daar IO: Oncogenic Met receptor induces cell-cycle progression in Xenopus oocytes independent of direct Grb2 and Shc binding or Mos synthesis, but requires phosphatidylinositol 3-kinase and Raf signaling. J Cell Physiol 2006, 207(1):271-285.

16. Ishimura A, Lee HS, Bong YS, Saucier C, Mood K, Park EK, Daar IO: Oncogenic Met receptor induces ectopic structures in Xenopus embryos. Oncogene 2006, 25(31):4286-4299.

17. Hardy WR, Li L, Wang Z, Sedy J, Fawcett J, Frank E, Kucera J, Pawson T: Combinatorial ShcA docking interactions support diversity in tissue morphogenesis. Science 2007, 317(5835):251-256.

18. Zheng Y, Zhang C, Croucher DR, Soliman MA, St-Denis N, Pasculescu A, Taylor L, Tate SA, Hardy WR, Colwill K, Dai AY, Bagshaw R, Dennis JW, Gingras AC, Daly RJ, Pawson T: Temporal regulation of EGF signalling networks by the scaffold protein Shc1. Nature 2013, 499(7457):166-171.

19. Northey JJ, Dong Z, Ngan E, Kaplan A, Hardy WR, Pawson T, Siegel PM: Distinct phosphotyrosine-dependent functions of the ShcA adaptor protein Are required for transforming growth factor beta (TGFbeta)induced breast cancer cell migration, invasion, and metastasis. J Biol Chem 2013, 288(7):5210-5222.

20. Mood K, Saucier C, Bong YS, Lee HS, Park M, Daar IO: Gab1 is required for cell cycle transition, cell proliferation, and transformation induced by an oncogenic met receptor. Mol Biol Cell 2006, 17(9):3717-3728.

21. Rodrigues GA, Naujokas MA, Park M: Alternative splicing generates isoforms of the met receptor tyrosine kinase which undergo differential processing. Mol Cell Biol 1991, 11(6):2962-2970.

22. Lemieux E, Bergeron S, Durand V, Asselin C, Saucier C, Rivard N: Constitutively active MEK1 is sufficient to induce epithelial-tomesenchymal transition in intestinal epithelial cells and to promote tumor invasion and metastasis. Int J Cancer 2009, 125(7):1575-1586.

23. di Fulvio M, Henkels KM, Gomez-Cambronero J: Short-hairpin RNAmediated stable silencing of Grb2 impairs cell growth and DNA synthesis. Biochem Biophys Res Commun 2007, 357(3):737-742.

24. Kisielow M, Kleiner S, Nagasawa M, Faisal A, Nagamine Y: Isoform-specific knockdown and expression of adaptor protein ShcA using small interfering RNA. Biochem J 2002, 363(Pt 1):1-5.

25. Quaroni A, Wands J, Trelstad RL, Isselbacher KJ: Epithelioid cell cultures from rat small intestine. Characterization by morphologic and immunologic criteria. J Cell Biol 1979, 80(2):248-265.

26. Seiden-Long I, Navab R, Shih W, Li M, Chow J, Zhu CQ, Radulovich N, Saucier C, Tsao MS: Gab1 but not Grb2 mediates tumor progression in Met overexpressing colorectal cancer cells. Carcinogenesis 2008, 29(3):647-655.

27. Scudiero DA, Shoemaker RH, Paull KD, Monks A, Tierney S, Nofziger TH, Currens MJ, Seniff D, Boyd MR: Evaluation of a soluble tetrazolium/ formazan assay for cell growth and drug sensitivity in culture using human and other tumor cell lines. Cancer Res 1988, 48(17):4827-4833.

28. Peschard P, Park M: From Tpr-Met to Met, tumorigenesis and tubes. Oncogene 2007, 26(9):1276-1285.

29. Trusolino L, Bertotti A, Comoglio PM: MET signalling: principles and functions in development, organ regeneration and cancer. Nat Rev Mol Cell Biol 2010, 11(12):834-848.
30. Gherardi E, Birchmeier W, Birchmeier C, Vande Woude G: Targeting MET in cancer: rationale and progress. Nat Rev Cancer 2012, 12(2):89-103.

31. Thiery JP, Acloque H, Huang RY, Nieto MA: Epithelial-mesenchymal transitions in development and disease. Cell 2009, 139(5):871-890.

32. Vachon $\mathrm{PH}$ : Integrin signaling, cell survival, and anoikis: distinctions, differences, and differentiation. J Signal Transduct 2011, 2011:738137.

33. Demers MJ, Thibodeau S, Noel D, Fujita N, Tsuruo T, Gauthier R, Arguin M, Vachon PH: Intestinal epithelial cancer cell anoikis resistance: EGFRmediated sustained activation of Src overrides Fak-dependent signaling to MEK/Erk and/or PI3-K/Akt-1. J Cell Biochem 2009, 107(4):639-654.

34. Gauthier R, Harnois C, Drolet JF, Reed JC, Vezina A, Vachon PH: Human intestinal epithelial cell survival: differentiation state-specific control mechanisms. Am J Physiol Cell Physiol 2001, 280(6):C1540-C1554.

35. Mendoza MC, Er EE, Blenis J: The Ras-ERK and PI3K-mTOR pathways: cross-talk and compensation. Trends Biochem Sci 2011, 36(6):320-328.

36. Kamikura DM, Khoury H, Maroun C, Naujokas MA, Park M: Enhanced transformation by a plasma membrane-associated met oncoprotein: activation of a phosphoinositide 3'-kinase-dependent autocrine loop involving hyaluronic acid and CD44. Mol Cell Biol 2000, 20(10):3482-3496

37. Zhu H, Naujokas MA, Park M: Receptor chimeras indicate that the met tyrosine kinase mediates the motility and morphogenic responses of hepatocyte growth/scatter factor. Cell Growth Differ 1994, 5(4):359-366.

38. Hanahan D, Weinberg RA: Hallmarks of cancer: the next generation. Cell 2011, 144(5):646-674

39. Tsanou E, Peschos D, Batistatou A, Charalabopoulos A, Charalabopoulos K: The E-cadherin adhesion molecule and colorectal cancer. A global literature approach. Anticancer Res 2008, 28(6A):3815-3826.

40. Delva E, Kowalczyk AP: Regulation of cadherin trafficking. Traffic 2009, 10(3):259-267.

41. Rosen K, Coll ML, Li A, Filmus J: Transforming growth factor-alpha prevents detachment-induced inhibition of c-Src kinase activity, BCl-XL down-regulation, and apoptosis of intestinal epithelial cells. J Bio/ Chem 2001, 276(40):37273-37279.

42. Fassetta M, D'Alessandro L, Coltella N, di Renzo MF, Rasola A: Hepatocyte growth factor installs a survival platform for colorectal cancer cell invasive growth and overcomes p38 MAPK-mediated apoptosis. Cell Signal 2006, 18(11):1967-1976.

43. Zeng Q, Chen S, You Z, Yang F, Carey TE, Saims D, Wang CY: Hepatocyte growth factor inhibits anoikis in head and neck squamous cell carcinoma cells by activation of ERK and Akt signaling independent of NFkappa B. J Biol Chem 2002, 277(28):25203-25208.

44. Tang MK, Zhou HY, Yam JW, Wong AS: c-Met overexpression contributes to the acquired apoptotic resistance of nonadherent ovarian cancer cells through a cross talk mediated by phosphatidylinositol 3-kinase and extracellular signal-regulated kinase 1/2. Neoplasia 2010, 12(2):128-138.

45. Watanabe S, Kishimoto T, Yokosuka O: Hepatocyte growth factor inhibits anoikis of pancreatic carcinoma cells through phosphatidylinositol 3-kinase pathway. Pancreas 2011, 40(4):608-614

46. Eggstein S, Franke M, Kutschka I, Manthey G, von Specht BU, Ruf G, Farthmann EH: Expression and activity of mitogen activated protein kinases in human colorectal carcinoma. Gut 1999, 44(6):834-838.

47. Wang Q, Ding Q, Dong Z, Ehlers RA, Evers BM: Downregulation of mitogen-activated protein kinases in human colon cancers. Anticancer Res 2000, 20(1A):75-83.

48. Yeh JJ, Routh ED, Rubinas T, Peacock J, Martin TD, Shen XJ, Sandler RS, Kim HJ, Keku TO, Der CJ: KRAS/BRAF mutation status and ERK1/2 activation as biomarkers for MEK1/2 inhibitor therapy in colorectal cancer. Mol Cancer Ther 2009, 8(4):834-843.

49. Sos ML, Fischer $\mathrm{S}$, Ullrich R, Peifer M, Heuckmann JM, Koker M, Heynck S, Stuckrath I, Weiss J, Fischer F, Michel K, Goel A, Regales L, Politi KA, Perera S, Getlik M, Heukamp LC, Ansen S, Zander T, Beroukhim R, Kashkar H, Shokat KM, Sellers WR, Rauh D, Orr C, Hoeflich KP, Friedman L, Wong KK, Pao W, Thomas RK: Identifying genotype-dependent efficacy of single and combined PI3K- and MAPK-pathway inhibition in cancer. Proc Natl Acad Sci U S A 2009, 106(43):18351-18356.

50. Sakakura C, Hagiwara A, Shirahama T, Nakanishi M, Yasuoka R, Fujita Y, Inazawa J, Abe T, Kohno M, Yamagishi $\mathrm{H}$ : Infrequent activation of mitogen-activated protein kinase in human colon cancers. Hepatogastroenterology 1999, 46(29):2831-2834. 
51. Lock LS, Frigault MM, Saucier C, Park M: Grb2-independent recruitment of Gab1 requires the C-terminal lobe and structural integrity of the Met receptor kinase domain. J Biol Chem 2003, 278(32):30083-30090.

52. Chong CR, Janne PA: The quest to overcome resistance to EGFR-targeted therapies in cancer. Nat Med 2013, 19(11):1389-1400.

53. Kuwai T, Nakamura T, Kim SJ, Sasaki T, Kitadai Y, Langley RR, Fan D, Hamilton SR, Fidler IJ: Intratumoral heterogeneity for expression of tyrosine kinase growth factor receptors in human colon cancer surgical specimens and orthotopic tumors. Am J Pathol 2008, 172(2):358-366

54. Liska D, Chen CT, Bachleitner-Hofmann T, Christensen JG, Weiser MR: HGF rescues colorectal cancer cells from EGFR inhibition via MET activation. Clin Cancer Res 2011, 17(3):472-482.

55. Krumbach R, Schuler J, Hofmann M, Giesemann T, Fiebig HH, Beckers T: Primary resistance to cetuximab in a panel of patient-derived tumour xenograft models: activation of MET as one mechanism for drug resistance. Eur J Cancer 2011, 47(8):1231-1243.

56. Straussman R, Morikawa T, Shee K, Barzily-Rokni M, Qian ZR, Du J, Davis A, Mongare MM, Gould J, Frederick DT, Cooper ZA, Chapman PB, Solit DB, Ribas A, Lo RS, Flaherty KT, Ogino S, Wargo JA, Golub TR: Tumour micro-environment elicits innate resistance to RAF inhibitors through HGF secretion. Nature 2012, 487(7408):500-504.

57. Wilson TR, Fridlyand J, Yan Y, Penuel E, Burton L, Chan E, Peng J, Lin E, Wang Y, Sosman J, Ribas A, Li J, Moffat J, Sutherlin DP, Koeppen H, Merchant M, Neve R, Settleman J: Widespread potential for growthfactor-driven resistance to anticancer kinase inhibitors. Nature 2012, 487(7408):505-509.

58. Corso S, Giordano S: Cell-autonomous and non-cell-autonomous mechanisms of HGF/MET-driven resistance to targeted therapies: from basic research to a clinical perspective. Cancer Discov 2013, 3(9):978-992.

59. Bardelli A, Corso S, Bertotti A, Hobor S, Valtorta E, Siravegna G, SartoreBianchi A, Scala E, Cassingena A, Zecchin D, Apicella M, Migliardi G, Galimi F, Lauricella C, Zanon C, Perera T, Veronese S, Corti G, Amatu A, Gambacorta M, Diaz LA Jr, Sausen M, Velculescu VE, Comoglio P, Trusolino L, Di Nicolantonio F, Giordano S, Siena S: Amplification of the MET receptor drives resistance to anti-EGFR therapies in colorectal cancer. Cancer Discov 2013, 3(6):658-673.

60. Cohen SJ, Cohen RB, Meropol NJ: Targeting signal transduction pathways in colorectal cancer-more than skin deep. J Clin Oncol 2005, 23(23):5374-5385.

61. Atabey N, Gao Y, Yao ZJ, Breckenridge D, Soon L, Soriano JV, Burke TR Jr, Bottaro DP: Potent blockade of hepatocyte growth factor-stimulated cell motility, matrix invasion and branching morphogenesis by antagonists of Grb2 Src homology 2 domain interactions. J Biol Chem 2001, 276(17):14308-14314.

62. Giubellino A, Gao Y, Lee S, Lee MJ, Vasselli JR, Medepalli S, Trepel JB, Burke TR Jr, Bottaro DP: Inhibition of tumor metastasis by a growth factor receptor bound protein 2 Src homology 2 domain-binding antagonist. Cancer Res 2007, 67(13):6012-6016.

63. Yu GZ, Chen Y, Long YQ, Dong D, Mu XL, Wang JJ: New insight into the key proteins and pathways involved in the metastasis of colorectal carcinoma. Oncol Rep 2008, 19(5):1191-1204.

doi:10.1186/1471-2407-14-240

Cite this article as: Pomerleau et al:: Met receptor-induced Grb2 or Shc signals both promote transformation of intestinal epithelial cells, albeit they are required for distinct oncogenic functions. BMC Cancer 2014 14:240

\section{Submit your next manuscript to BioMed Central and take full advantage of:}

- Convenient online submission

- Thorough peer review

- No space constraints or color figure charges

- Immediate publication on acceptance

- Inclusion in PubMed, CAS, Scopus and Google Scholar

- Research which is freely available for redistribution 